\title{
Is There a Relationship Between the Types of Nasal Septal Deviation and Morphologic Changes of Oropharyngeal Structures?
}

\author{
(1D) Hüseyin Sarı, (1) Esmail Abdulahi Ahmed, (1) Sabire Sitare Sarıçam, (D) Ayşe Enise Göker, (D) Ayça Başkadem Yılmazer, \\ (D) Yavuz Atar, (1) Güler Berkiten, (D) Yavuz Uyar
}

University of Health Sciences Turkey, Prof. Dr. Cemil Taşçığlu City Hospital, Clinic of Otorhinolaryngology-head and Neck Surgery, i̇stanbul, Turkey

\section{Abstract}

Objective: To evaluate the relationship between types of nasal septal deviation and other oropharyngeal structures that affected the upper airway respiratory tract.

Methods: A total of 120 participants were included in the study: 100 patients with nasal septal deviation and 20 healthy people who had no nasal septal deviation (control group). The oropharyngeal examination findings, modified Mallampati index, retroglossal space, tonsil size, and pharyngeal space were recorded for each patient. The types of nasal septal deviation were compared in terms of the aforementioned parameters.

Results: The types of nasal septal deviation were compared in terms of the Mallampati score, retroglossal space, tonsil grade, and pharyngeal space. Significant differences were present between the Mallampati scores and retroglossal space values and types of nasal septal deviation $(p=0.001, p=0.001)$. Types of nasal septal deviation were divided into five groups as follows: Group 1, septal tilt; group 2, C-shaped anteroposterior deviation; group 3, C-shaped cephalocaudal deformity; group 4, S-shaped anteroposterior deformity; group 5, S-shaped cephalocaudal deformity. Group 6 was the control group. Groups 1, 2, and 4 had higher Mallampati scores than group 6 . Group 3 and 5 did not differ compared to group 6. Groups 1, 2, 3, 4, and 5 had higher retroglossal space values than group 6 . There was no difference between the other groups 1, 2, 3, 4 and 5. Tonsil grade and pharyngeal space values did not differ significantly between all groups ( $p>0.05$ ).

Conclusion: Airway passage changes depend on various factors from childhood to adulthood. The change in airway resistance due to nasal septum deviation affects the airflow and oropharyngeal anatomical structures. In our study, it was observed that nasal septum deviation affected the Mallampati scores and retroglossal space values.

Keywords: Nasal septal deviation, Mallampati, tonsil grade

\section{INTRODUCTION}

The effects of respiratory function on craniofacial development have been studied for a long time. Various structural disorders of the upper airway induce mouth breathing and gradually lead to different maxillofacial and oropharyngeal morphologic changes (1). The shape and dimensions of the upper airway are involved in the pathogenesis of obstructive sleep apnea. Although the weight and neck thickness are critical in airway collapse, there is a multifactorial etiology involving the nose, palate, tonsils, and pharyngeal morphology $(2,3)$.

One of the most common causes of mouth breathing, upper airway obstruction, and related sleep apnea is the nasal septal deviation. The most common reason for admission to otolaryngology outpatient clinics due to nasal obstruction is nasal septal deviation. It ranks first among nasal surgeries performed due to nasal congestion. This nasal resistance 
in respiratory pathologies plays an important role in the development of oropharyngeal and maxillofacial structures, especially in childhood. Although there is no known cause of nasal septal deviation, congenital deformities, prenatal, natal or postnatal traumas, and external traumas are the most common causes of nasal septal deviation. However, breathing through the mouth, applying pressure to the palate with the tongue, and finger sucking are also among the common causes of septal deviation (4).

So, it is possible to talk about a vicious circle in which structural deformities of different structures of the upper airway could lead to gradual deformation of the other pharyngeal structures. Both Nakata et al. (5) and Park et al. (6) reported in their studies that correction of nasal septal deviation had a functional influence on the improvement of obstructive sleep apnea.

In this study, we evaluated the relationship between types of nasal septal deviation and other oropharyngeal structures that had a positive effect on the upper airway respiratory tract.

\section{METHODS}

This prospective study enrolled 120 patients diagnosed with nasal septal deviation. A total of 100 patients with nasal septal deviation and 20 patients without nasal septal deviation (control group) were included in the study. The study was conducted between October 2018 and March 2019. The Okmeydanı Training and Research Hospital Ethical Committee Institutional Review Board approval were obtained (no: 48670771-514.10). Written informed consent was obtained from patients who participated in this study. Patients who attended an outpatient clinic with nasal congestion, snoring problems, and sleep apnea were included. Exclusion criteria included previous nasal and oropharyngeal surgeries, nasal polyposis, inferior turbinate hypertrophy, concha bullosa, allergic rhinitis, major nasal trauma in childhood, and chronic systemic diseases.

All patients underwent a complete history and otolaryngological examination, including nasopharyngoscopy and laryngoscopy. Computed tomography of the paranasal sinus was used to evaluate the type of septal deviation. The classification of nasal septal deviation was modified from that of Guyuron et al. (7). Deviations due to nasal septal spurs present in Guyuron classification were excluded in this study because they minimally affect the nasal airway resistance. Septal deviations were divided into five groups. Group 1 included septal tilts. The septal tilt was defined as a septum that had no curve; it was tilted to one side of the nose in relation to the sagittal plane as the maxillary crest remained straight. Group two included C-shaped anteroposterior deviation, where the septum had a curvature rather than being tilted. The maxillary crest and nasal spine have deviated. Group three included C-shaped cephalocaudal deformity. Group four included S-shape anteroposterior deformity. Group five included S-shape cephalocaudal deformity. In the S category, the septum had two curvatures next to each other in opposing directions. The oropharyngeal examination findings, modified Mallampati index, retroglossal space, tonsil size, and pharyngeal space were recorded for each patient. Oropharyngeal morphology was evaluated using modified Mallampati index. The modified Mallampati index was evaluated based on the visualization of the oropharynx (8). The patient was asked to open the mouth widely with the tongue left in place and oropharyngeal crowding was graded as follows: Grade 1: Tonsils, pillars, and soft palate were clearly visible; grade 2: The uvula, pillars, and upper pole were visible; grade 3: Only part of the soft palate was visible; grade 4: The tonsils, pillars, and base of the uvula could not be seen, and only the hard palate was visible. The tonsillar grade was assessed using a four-point ordinal scale $(8,9)$. Grade 1 tonsils were in the tonsillar fossa, barely seen behind the anterior pillars. Grade 2 tonsils were visible behind the anterior pillars. Grade 3 tonsils extended three-quarters of the way to the midline. Grade 4 tonsils were completely obstructing the airway, also known as "kissing" tonsils. The retropharyngeal space evaluation was performed using the retroglossal grading system $(9,10)$. We evaluated the retroglossal space using nasopharyngeal endoscopy. In grade 1, the retroglossal space is widely patent, allowing visualization of the larynx (normal). In grade 2 , the retroglossal space allows visualization of the vocal folds, and the opposing walls are not in proximity (small). In grade 3 , the retroglossal space allows only visualization of the posterior arytenoids (very small). In grade 4, the retroglossal space is in contact with the opposing walls (obstructed). The pharyngeal space (pharyngeal grade) was assessed using a four-point ordinal scale $(9,11)$. The pharyngeal grading system is as follows. In class 1, the palatopharyngeal arch intersects at the edge of the tongue. In class 2, the palatopharyngeal arch intersects at 25\% or more of the tongue diameter. In class 3 , the palatopharyngeal arch intersects at $50 \%$ or more of the tongue diameter. In class 4 , the palatopharyngeal arch intersects at $75 \%$ or more of the tongue diameter. Then, the relationship between types of nasal septal deviation and the morphology of the aforementioned oropharyngeal structures was evaluated.

\section{Statistical Analysis}

The sample size was calculated using the power and sample size analysis program. A sample size of 20 patients per group provided approximately $80 \%$ power to detect alpha: 0.05 level between the groups. 
Statistical analyses of the data were conducted using IBM SPSS Statistics 22 (IBM SPSS, İstanbul, Turkey). The data were analyzed using descriptive statistical methods (mean and standard deviation). Shapiro-Wilk test was used to assess the normal distribution of the parameters. Kruskal-Wallis test was used for comparing two or more independent samples of equal or different sample sizes. Mann-Whitney $U$ test was used for the post-hoc comparison test. Bonferroni correction was calculated for Mann-Whitney $U$ test. The results were evaluated using the $95 \%$ confidence intervals, and the level of significance was set at $p<0.05$.

\section{RESULTS}

The study group included 120 consecutive patients. Seventytwo of them (60.0\%) were males and 48 (40.0\%) were females. The mean age was $34.19 \pm 13.22$ years (range: $17-70$ years). There was no significant difference between the septal deviation groups with respect to gender and age $(p=0.367$; $p=0.191$ ) (Table 1).

Table 1. The distribution of the patients according to age and gender

\begin{tabular}{|l|l|l|l|}
\hline \multicolumn{2}{|l|}{} & Minimum-maximum & Mean \pm SD \\
\hline \multicolumn{2}{|l|}{ Age (years) } & $17-70$ & $34.19 \pm 13.22$ \\
\hline \multirow{2}{*}{ Age (years) } & Females & $17-68$ & $34.04 \pm 13.28$ \\
\cline { 2 - 4 } & Males & $17-70$ & $34.29 \pm 13.27$ \\
\hline \multicolumn{2}{|l|}{} & N & $\%$ \\
\hline \multirow{2}{*}{ Gender } & Females & 48 & 40.0 \\
\cline { 2 - 4 } & Males & 72 & 60.0 \\
\hline \multicolumn{2}{|l}{ SD: Standard deviation }
\end{tabular}

The types of nasal septal deviation were compared in terms of the Mallampati score, retroglossal space, tonsil grade, and pharyngeal space. There were significant differences between Mallampati scores and retroglossal space values and types of nasal septal deviation $(p=0.001 ; p=0.001)$ (Table 2$)$. When the Mallampati scores were compared within the groups, groups 1,2 , and 4 had significantly higher scores than group 6 . There was no difference between groups 3, 5, and 6 (Table 3). When retroglossal space values were compared between groups, groups 1, 2, 3, 4, and 5 had significantly higher values than the control group (group 6). There was no difference between the other groups 1, 2, 3, 4 and 5 (Table 3).

Tonsil grade and pharyngeal space values did not differ significantly between all groups ( $p=0.055 ; p=0.396)$ (Table 2 ).

\section{DISCUSSION}

Tongue base hypertrophy, tonsillar hypertrophy, hypertrophy in the lateral pharyngeal bands, and narrowing in retroglossal space occur in different degrees with aging. In childhood, oropharyngeal findings are generally normal, unlike the findings of sleep apnea syndrome in adults. As people get older, the soft tissues of the nose and pharynx change. Many environmental and genetic factors trigger this change, which are not fully addressed. Most of the studies focused on oropharyngeal and nasal pathologies in sleep apnea syndrome. Nasal septal deviation may have an indirect role in the growth of the maxilla that can affect the development of obstructive sleep apnea, together with other pharyngeal structures, such as the position of the palate, tonsils, fauces, and retropharyngeal space $(8,9,12)$.

Table 2. Comparison between the types of nasal septal deviation in terms of the Mallampati score, retroglossal space, tonsil grade, and pharyngeal space

\begin{tabular}{|c|c|c|c|c|c|c|c|c|}
\hline \multirow[t]{2}{*}{$\begin{array}{l}\text { Septal } \\
\text { deviation } \\
\text { types }\end{array}$} & $\begin{array}{l}\text { Group } 1 \\
\text { (septal tilt) } \\
(n=20)\end{array}$ & $\begin{array}{l}\text { Group } 2 \\
\text { (C-shaped } \\
\text { anteroposterior } \\
\text { deviation) } \\
(\mathrm{n}=20)\end{array}$ & $\begin{array}{l}\text { Group } 3 \\
\text { (C-shaped } \\
\text { cephalocaudal } \\
\text { deformity) } \\
(n=20)\end{array}$ & $\begin{array}{l}\text { Group } 4 \\
\text { (S-shaped } \\
\text { anteroposterior } \\
\text { deformity) } \\
(\mathrm{n}=20)\end{array}$ & $\begin{array}{l}\text { Group } 5 \\
\text { (S-shaped } \\
\text { cephalocaudal } \\
\text { deformity) } \\
(n=20)\end{array}$ & $\begin{array}{l}\text { Group } 6 \\
\text { (control) } \\
(n=20)\end{array}$ & & \multirow[t]{2}{*}{$* p$} \\
\hline & $\begin{array}{l}\text { Mean } \pm \text { SD } \\
\text { (median) }\end{array}$ & $\begin{array}{l}\text { Mean } \pm \text { SD } \\
\text { (median) }\end{array}$ & $\begin{array}{l}\text { Mean } \pm \text { SD } \\
\text { (median) }\end{array}$ & $\begin{array}{l}\text { Mean } \pm \text { SD } \\
\text { (median) }\end{array}$ & $\begin{array}{l}\text { Mean } \pm \text { SD } \\
\text { (median) }\end{array}$ & $\begin{array}{l}\text { Mean } \pm \text { SD } \\
\text { (median) }\end{array}$ & $\begin{array}{l}* *(\text { IQR: } \\
25 \%-75 \%)\end{array}$ & \\
\hline $\begin{array}{l}\text { Retroglossal } \\
\text { space }\end{array}$ & $\begin{array}{l}2.25 \pm 0.79 \\
(2.00)\end{array}$ & $\begin{array}{l}2.05 \pm 0.83 \\
(2.00)\end{array}$ & $\begin{array}{l}1.85 \pm 0.67 \\
(2.00)\end{array}$ & $\begin{array}{l}2.30 \pm 0.73 \\
(2.00)\end{array}$ & $\begin{array}{l}2.05 \pm 0.76 \\
(2.00)\end{array}$ & $\begin{array}{l}1.15 \pm 0.37 \\
(1.00)\end{array}$ & $1.00-3.00$ & 0.001 \\
\hline Tonsil grade & $\begin{array}{l}1.75 \pm 0.72 \\
(2.00)\end{array}$ & $\begin{array}{l}1.75 \pm 0.55 \\
(2.00)\end{array}$ & $\begin{array}{l}1.65 \pm 0.67 \\
(2.00)\end{array}$ & $\begin{array}{l}2.00 \pm 0.92 \\
(2.00)\end{array}$ & $\begin{array}{l}2.00 \pm 0.73 \\
(2.00)\end{array}$ & $\begin{array}{l}1.35 \pm 0.49 \\
(1.00)\end{array}$ & $1.00-2.00$ & 0.055 \\
\hline
\end{tabular}


Some studies have indicated that the nasal septal deviations affected total nasal resistance and airflow parameters in the nasal cavity (13). For this reason, the type of septum deviation may affect the development of oropharyngeal and nasal pathologies. Moreover, Park et al. (6) stated that correcting nasal pathologies and relieving nasal patency had an important role in the improvement of obstructive sleep apnea. However, Morinaga et al. (9) demonstrated that both palatal and pharyngeal morphologies were important factors for successful nasal surgery.

This shows the importance of getting a comprehensive evaluation and understanding of the relationship between different nasal septal deviations and pharyngeal morphology of the patients. In our study, we categorized patients according to the type of nasal septal deviation to compare between the types of nasal deviation in terms of the Mallampati score, tonsillar size, narrowness of the fauces, and retropharyngeal space.

Previous studies showed that the nasal airflow and amount of pharyngeal soft tissue were associated with each other $(9,14)$. Our results revealed that retroglossal space differed in all types of septum deviations compared with the control group. However, the modified Mallampati index did not differ in S- and C-shaped cephalocaudal deviations. Tonsil grade and pharyngeal space did not differ between the groups (Table 2, 3). Anterior and posterior nasal septal deviations affect the nasal airflow through the nasal

Table 3. Comparison of Mallampati score and retroglossal space within groups

\begin{tabular}{|c|c|c|}
\hline & Mallampati score & Retroglossal space \\
\hline & *p & $* p$ \\
\hline Groups 1 and 2 & 0.216 & 0.507 \\
\hline Groups 1 and 3 & 0.016 & 0.103 \\
\hline Groups 1 and 4 & 0.533 & 0.714 \\
\hline Groups 1 and 5 & 0.200 & 0.474 \\
\hline Groups 1 and 6 & 0.001 & 0.001 \\
\hline Groups 2 and 3 & 0.183 & 0.416 \\
\hline Groups 2 and 4 & 0.510 & 0.332 \\
\hline Groups 2 and 5 & 0.884 & 0.989 \\
\hline Groups 2 and 6 & 0.004 & 0.001 \\
\hline Groups 3 and 4 & 0.054 & 0.058 \\
\hline Groups 3 and 5 & 0.277 & 0.385 \\
\hline Groups 3 and 6 & 0.046 & 0.001 \\
\hline Groups 4 and 5 & 0.460 & 0.288 \\
\hline Groups 4 and 6 & 0.001 & 0.001 \\
\hline Groups 5 and 6 & 0.009 & 0.001 \\
\hline
\end{tabular}

base more than the cephalocaudal deviations. Therefore, there was no significant change in modified Mallampati index scores in cephalocaudal septum deviation groups compared with the control group.

Akbay et al. (15) stated that the septal deviation influenced the depth and curve of the palatal bone. Thus, posterior septal deviation and affected maxillo-palatal arch result in nasal obstruction. Friedman et al. (8) reported that both the retroglossal space and Mallampati score played an important role in the upper airway obstruction. In our study, it was observed that the Mallampati score was high, and the retroglossal space was narrower in those with septum deviation. Moreover, similar to the results of our study, Liistro et al. (2) found that the Mallampati and nasal obstruction scores were significant in patients with the risk of obstructive sleep apnea.

The etiology of tonsillar hypertrophy is not exactly known. However, diet, genetics, and humoral change may play a role (16). The recurrent and chronic inflammation of palatine tonsils sometimes result in hypertrophy (17) and, therefore, are not expected to be associated with types of septal deviation. In our study, we also did not observe a significant difference when we compared between types of septal deviation in terms of tonsil size.

Lateral pharyngeal band hypertrophy narrowed the pharyngeal space, which is the distance between two palatopharyngeal arches. The narrowing of this region increases with weight gain and causes obstructive sleep apnea syndrome. We did not see any difference between types of septal deviation in terms of the pharyngeal space. This showed that the septal deviation has no effect on the narrowing of the pharyngeal space.

\section{CONCLUSION}

The airway passage changes depend on various factors from childhood to adulthood. The change in airway resistance due to nasal septum deviation affects the airflow and oropharyngeal anatomical structures. Long-term prospective cohort studies involving the pediatric population are needed to understand this effect. In our study, it was observed that nasal septum deviation affected the Mallampati scores and retroglossal space.

\section{Ethics}

Ethics Committee Approval: The Okmeydanı Training and Research Hospital Ethical Committee Institutional Review Board approval were obtained (no: 48670771-514.10).

Informed Consent: Written informed consent was obtained from patients who participated in this study. 
Peer-review: Externally and internally peer-reviewed.

\section{Authorship Contributions}

Concept: Y.A., Design: Y.U., Data Collection or Processing: E.A.A., Analysis or Interpretation: A.B.Y., G.B., Y.U., Literature Search: A.E.G., Writing: H.S., S.S.S.

Conflict of Interest: No conflict of interest was declared by the authors.

Financial Disclosure: The authors declared that this study received no financial support.

\section{REFERENCES}

1. Barceló X, Mirapeix RM, Bugés J, Cobos A, Domingo C. Oropharyngeal examination to predict sleep apnea severity. Arch Otolaryngol Head Neck Surg 2011;137:990-6.

2. Liistro G, Rombaux P, Belge C, Dury M, Aubert G, Rodenstein DO. High Mallampati score and nasal obstruction are associated risk factors for obstructive sleep apnoea. Eur Respir J 2003;21:248-52.

3. Wanzeler AMV, Renda MDO, de Oliveira Pereira ME, Alves-Junior SM, Tuji FM. Anatomical relation between nasal septum deviation and oropharynx volume in different facial patterns evaluated through cone beam computed tomography. Oral Maxillofac Surg 2017;21:341-6.

4. Shapiro PA. Effects of nasal obstruction on facial development. J Allergy Clin Immunol 1988;81(5 Pt 2):967-71.

5. Nakata S, Noda A, Yasuma F, Morinaga M, Sugiura M, Katayama N, et al. Effects of nasal surgery on sleep quality in obstructive sleep apnea syndrome with nasal obstruction. Am J Rhinol 2008;22:59-63.

6. Park CY, Hong JH, Lee JH, Lee KE, Cho HS, Lim SJ, et al. Clinical effect of surgical correction for nasal pathology on the treatment of obstructive sleep apnea syndrome. PLoS One 2014;4;9:e98765.
7. Guyuron B, Uzzo CD, Scull H. A practical classification of septonasal deviation and an effective guide to septal surgery. Plast Reconstr Surg 1999;104:2202-9; discussion 2210-2.

8. Friedman M, Tanyeri H, La Rosa M, Landsberg R, Vaidyanathan K, Pieri $\mathrm{S}$, et al. Clinical predictors of obstructive sleep apnea. Laryngoscope 1999;109:1901-7.

9. Morinaga M, Nakata S, Yasuma F, Noda A, Yagi H, Tagaya M, et al. Pharyngeal morphology: a determinant of successful nasal surgery for sleep apnea. Laryngoscope 2009;119:1011-6.

10. Woodson BT, Naganuma H. Comparison of methods of airway evaluation in obstructive sleep apnea syndrome. Otolaryngol Head Neck Surg 1999;120:460-3.

11. Tsai WH, Remmers JE, Brant R, Flemons WW, Davies J, Macarthur C. A decision rule for diagnostic testing in obstructive sleep apnea. Am J Respir Crit Care Med 2003;167:1427-32

12. Kim YM, Rha KS, Weissman JD, Hwang PH, Most SP. Correlation of asymmetric facial growth with deviated nasal septum. Laryngoscope 2011;121:1144-8.

13. Li L, Zang H, Han D, London NR Jr. Impact of Varying Types of Nasal Septal Deviation on Nasal Airflow Pattern and Warming Function: A Computational Fluid Dynamics Analysis. Ear Nose Throat J 2019;145561319872745.

14. Michels Dde S, Rodrigues Ada M, Nakanishi M, Sampaio AL, Venosa AR. Nasal involvement in obstructive sleep apnea syndrome. Int J Otolaryngol 2014;2014:717419.

15. Akbay E, Cokkeser Y, Yilmaz O, Cevik C. The relationship between posterior septum deviation and depth of maxillopalatal arch. Auris Nasus Larynx 2013;40:286-90.

16. Yilmaz T, Koçan EG, Besler HT. The role of oxidants and antioxidants in chronic tonsillitis and adenoid hypertrophy in children. Int J Pediatr Otorhinolaryngol 2004;68:1053-8.

17. Önal M, Yılmaz T, Bilgiç E, Müftüoğlu SF, Kuşçu O, Günaydın RÖ. Apoptosis in chronic tonsillitis and tonsillar hypertrophy. Int J Pediatr Otorhinolaryngol 2015;79:191-5. 